\title{
O DESENVOlVIMENTO DO PENSAMENTO CRÍTICO SOBRE EDUCAÇÃO AMBIENTAL E MEIO AMBIENTE: CONCEPÇÃO DOS ALUNOS DO ENSINO MÉDIO DO MUNICÍPIO DE UNIFLOR - PR
}

\author{
THE DEVELOPMENT OF CRITICAL THINKING ON ENVIRONMENTAL \\ EDUCATION AND THE ENVIRONMENT: PROJECT OF HIGH SCHOOL \\ STUDENTS FROM UNIFLOR - PR
}

DOI: http://dx.doi.org/10.23926/RPD.2526-2149.2020.v5.n1.p234-248.id578

\section{Bianca Fernandes Guimarães Severo dos Santos \\ Mestra em Ensino \\ (UNESPAR) \\ Professora da Secretaria da \\ Educação e do Esporte \\ (SEED-PR) \\ bia-fer22@hotmail.com}

\author{
Marcia Regina Royer \\ Doutora em Agronomia \\ (UEM) \\ Professora da Universidade \\ Estadual do Paraná, campus \\ Paranavaí (UNESPAR) \\ marciaroyer@yahoo.com.br
}

\begin{abstract}
Resumo: Discussões a respeito de questões ambientais têm conquistado espaço na sociedade e a escola como uma das principais instituições de socialização do ser humano possui um papel fundamental no desenvolvimento de uma Educação Ambiental emancipatória, capacitando o indivíduo para viver harmonicamente com o Meio Ambiente. O objetivo da pesquisa foi analisar a concepção dos alunos do Ensino Médio de uma instituição pública do município de Uniflor sobre Educação Ambiental, além de buscar compreender a percepção sobre Meio Ambiente como participantes das ações humanas na natureza. Os dados foram coletados por meio de questionários e os resultados indicaram uma concepção totalmente conservacionista de Meio Ambiente. Logo, os professores desses alunos, ao planejarem atividades em Educação Ambiental, devem considerar esses resultados a fim de construir, coletivamente com toda a comunidade escolar, um conceito de Meio Ambiente mais amplo e crítico.
\end{abstract}

Palavras-chave: Questões ambientais; Conservacionista; Escola.

\begin{abstract}
Discussions about environmental issues have gained space in society and the school as one of the main institutions of socialization of the human being has a fundamental role in the development of an emancipatory Environmental Education, enabling the individual to live in harmony. with the Environment. The objective of the research was to analyze the conception of High School students of a public institution in the city of Uniflor about Environmental Education, as well as to understand the perception of Environment as participants of human actions in nature. The data were collected through questionnaires and the results indicated a totally conservationist conception off environment. Therefore, the teachers of these students, when planning activities in Environmental Education, must consider these results in order to build, collectively with the whole school community, a broader and critical environment concept.
\end{abstract}

Keywords: Environmental issues; Conservationist; School. 


\section{INTRODUÇÃO}

O primeiro evento responsável por discutir as questões ambientais foi a Conferência das Nações Unidas Sobre Meio ambiente, conhecida como Conferência de Estocolmo, em 1972. A partir dessa data se passaram quatro décadas em que a Educação Ambiental tem sido discutida no planeta.

No Brasil, pela Lei no 9.795 de 27 de abril de 1999, foi decretada então a Política Nacional de Educação Ambiental, e que, em 2019, completou 20 anos. No artigo $1^{\circ}$, desta lei, a Educação Ambiental é caracterizada como processos por meio dos quais o indivíduo e a coletividade constroem valores sociais, conhecimentos, habilidades, atitudes e competências voltadas para a conservação do meio ambiente, bem de uso comum do povo, essencial à sadia qualidade de vida e sua sustentabilidade (BRASIL, 1999).

É evidente que a humanidade tem se preocupado com as questões ambientais nas últimas décadas e sua ação no ambiente em que vive. Gerar nos seres humanos a capacidade de desenvolver habilidades intelectuais transformadoras das ações e atitudes no meio em que vivemos, e ampliar essas ações para a comunidade local promovendo uma abordagem crítica sobre questões socioambientais é um dos objetivos da Educação Ambiental. Esta tem como função entender a nossa relação com o meio em que vivemos e refletir de que forma podemos viver harmonicamente.

Segundo Reigota (1998, p. 44), "A Educação Ambiental aponta para propostas pedagógicas centradas na conscientização, mudança de comportamento, desenvolvimento de competências, capacidade de avaliação e participação dos educandos”.

A Política Nacional de Educação Ambiental, Art. $9^{\circ}$, estabeleceu que a Educação Ambiental integrasse os currículos educacionais em todos os níveis e modalidades de ensino. Se compararmos a evolução do ensino no Brasil, em 1950, apenas 36,2\% das crianças de 7 a 14 anos tinha acesso à escola. Em 1990, esse índice havia atingido 88\%, observa-se assim, uma mudança significativa nesse cenário, pois o acesso à educação pública é um direito que tem se universalizado (GOLDEMBERG, 1993). Segundo o censo de 2016, publicado pelo Instituto Nacional de Estudos e Pesquisas Educacionais Anísio Teixeira (INEP), são 12,2 milhões de matrículas nos anos finais do ensino fundamental (INEP, 2016). Portanto, a escola é uma das primeiras instituições sociais em que um indivíduo está inserido, sendo assim, além de transmitir, reformular e construir conhecimento, o órgão escolar também promove relações de cidadania entre os indivíduos e o meio em que vivem, na sociedade contemporânea.

Pérez Gómez (1998, p. 15) argumenta que 


\begin{abstract}
A escola deve provocar o desenvolvimento de conhecimentos, ideias, atitudes e pautas de comportamento que permitam sua incorporação eficaz no mundo civil no âmbito da liberdade do consumo, da liberdade de escolha e participação política, da liberdade e responsabilidade na esfera da vida familiar. Características bem diferentes daquelas que requer sua incorporação submissa e disciplinada, para a maioria, no mundo do trabalho assalariado.
\end{abstract}

Dessa forma, a escola é um campo apropriado para o letramento científico de todas as áreas do conhecimento, inclusive debater sobre as questões ambientais e a formação de indivíduos reflexivos transformando a sua visão sobre as questões socioambientais. Nesse contexto, Guimarães (2000) tem caracterizado que o espaço escolar é um ambiente propício para o desenvolvimento da educação formal e de uma alfabetização científica para a cidadania. Em defesa de uma educação ambiental crítica no campo de educação, Tozoni-Reis (2004) discute o conceito de educação para evidenciar que, enquanto prática social construída historicamente, a educação é espaço de disputa entre diferentes concepções de mundo, de homem e de sociedade. Ainda para Tozoni-Reis (2001, p. 41) "a educação e a educação ambiental instrumentalizam o sujeito para a prática social, inclusive em sua dimensão ambiental; instrumentalização que poderá ser tão democrática quanto for democrática a sociedade que a constrói”.

Num outro extremo, a abordagem da Educação Ambiental conservacionista foca em temas como lixo, reciclagem, água, em datas restritas como o Dia da árvore, Dia do Meio Ambiente, propostas integradas no currículo escolar e assim, escola e professores acreditam estar desenvolvendo uma Educação Ambiental de qualidade. Essa linha mais tradicional simplifica ou reduz fenômenos complexos da realidade (GUIMARÃES, 2007).

Na visão de Dias (2004), a Educação Ambiental na escola não deve ser conservacionista, ou seja, aquela cujos ensinamentos conduzem ao uso racional dos recursos Naturais e à manutenção de um nível ótimo de produtividade dos ecossistemas naturais ou gerenciados pelo Homem, mas aquela educação voltada para o meio ambiente que implica uma profunda mudança de valores, em uma nova visão de mundo, o que ultrapassa bastante o estado conservacionista.

Dessa forma, o objetivo desta pesquisa é averiguar as concepções de alguns alunos do Ensino Médio de uma instituição pública do município de Uniflor, região noroeste do Estado do Paraná, apresentam sobre a Educação Ambiental e o Meio Ambiente.

Com este objetivo acredita-se que é possível observar se os mesmos apresentam uma concepção com caráter crítico das ações humanas ou se mantém conservador não provocando mudanças significativas na sociedade. 


\section{Metodologia}

A pesquisa possui caráter qualitativo e os dados foram coletados através de questionários aplicados em três séries (primeira, segunda e terceira) do Ensino Médio. Por conseguinte, a amostra foi constituída de 9, 15 e 14 alunos, respectivamente do primeiro, segundo e terceiro anos de um colégio público da cidade de Uniflor, Estado do Paraná, totalizando 38 participantes na pesquisa. Os participantes da pesquisa tiveram suas identidades preservadas, sendo usadas as letras A, B e C para as respostas dos alunos da primeira, segunda e terceira séries, respectivamente. Às letras foram acrescidos os algarismos 1, 2, 3, e, assim, sucessivamente, conforme as respostas selecionadas para a discussão.

Um questionário com cinco questões do tipo descritiva e objetiva foi entregue aos alunos com o objetivo de analisar à concepção deles sobre:

1) Educação Ambiental;

2) Meio Ambiente;

3) Os principais meios pelos quais se informam sobre questões ambientais;

4) Quais disciplinas deveriam trabalhar esse tema;

5) De que forma esse trabalho poderia ser desenvolvido.

Gil (2008, p. 124) afirma que: “O questionário constitui hoje uma das mais importantes técnicas disponíveis para a obtenção de dados nas pesquisas sociais."

Depois da organização dos dados coletados no questionário, estes foram separados de acordo com à série de cada aluno e analisamos à primeira questão de todos os alunos, à segunda questão de todos os alunos e assim sucessivamente selecionando as palavras chaves das respostas que forneceram os dados para a discussão do tema. Para análise dos dados, utilizouse o método de análise de conteúdo.

\section{RESUlTADOS E DISCUSSÃO}

Considerou-se como ponto inicial para análise do questionário dos alunos do Ensino Médio, o conhecimento acerca dos conceitos ambientais relacionados com à educação, a fim de analisar como estão sendo definidas as dimensões ambiental pelos estudantes nascidos após a lei $\mathrm{n}^{\circ} 9.795$ de 27 de abril de 1999, onde determina que todas as disciplinas e todas às séries devem trabalhar à Educação Ambiental. Questionou-se primeiramente: "O que você entende por Educação Ambiental?" Nesta questão, selecionamos as respostas de somente quatro alunos de cada série entre os entrevistados pelas características das respostas. Também, ressalta-se que 
no primeiro ano, três alunos "informaram que não saberiam as respostas" e no segundo ano, um participante não respondeu à questão formulada.

No Quadro 1 consta as quatro respostas selecionadas, respondidas pelos alunos do primeiro, segundo e terceiro anos, respectivamente.

Quadro 1 - Concepção dos alunos do Ensino Médio sobre Educação Ambiental.

\begin{tabular}{|c|l|}
\hline $\begin{array}{c}\text { Identificação dos } \\
\text { alunos }\end{array}$ & \multicolumn{1}{c|}{ Respostas dos alunos } \\
\hline \multicolumn{2}{|c|}{ Concepção dos alunos do primeiro ano sobre Educação Ambiental } \\
\hline A1 & $\begin{array}{l}\text { "Uma educação que propicia o cuidado e conservação do meio } \\
\text { ambiente". }\end{array}$ \\
\hline A2 & "É o estudo da natureza". \\
\hline A3 & $\begin{array}{l}\text { "A educação ambiental é mostrar para os outros e fazer eles } \\
\text { entenderem sobre os problemas ambientais e se conscientizarem a } \\
\text { mudar e descartar o lixo corretamente e evitar queimadas". }\end{array}$ \\
\hline A4 & "À educação ambiental estuda a escola e o local onde vivemos". \\
\hline Concepção dos alunos do segundo ano sobre Educação Ambiental \\
\hline B1 & $\begin{array}{l}\text { "Cuidar do meio ambiente, não jogando lixo em lugares proibidos e } \\
\text { evitar a poluição". }\end{array}$ \\
\hline B2 & "Manter o ambiente limpo e saudável". \\
\hline B3 & "Ser responsável pelo meio ambiente, respeitar o meio ambiente". \\
\hline B4 & $\begin{array}{l}\text { "É o ensino sobre o meio ambiente para não jogar lixo no chão, não } \\
\text { poluir". }\end{array}$ \\
\hline Concepção dos alunos do terceiro ano sobre Educação Ambiental \\
\hline C1 & $\begin{array}{l}\text { "É aprender sobre o meio ambiente e saber usar o aprendizado para } \\
\text { viver e cuidar do nosso ambiente". }\end{array}$ \\
\hline C2 & "Conscientizar/ensinar o indivíduo a preservar a natureza". \\
\hline C3 & $\begin{array}{l}\text { "Á educação ambiental é as pessoas terem competência e cuidar do } \\
\text { nosso meio ambiente". }\end{array}$ \\
\hline "É respeitar o meio ambiente e fazer sua parte como cidadão" \\
\hline
\end{tabular}

Fonte: Autoras.

Pela resposta do aluno A3 é possível verificar a influência de uma Educação Ambiental crítica, pois busca à transformação da sociedade a partir da conscientização e mudança de comportamento. Porém, a conscientização está relacionada ao lixo, queimadas, desmatamentos, ou seja, a temas conservacionistas, muito distante das questões ambientais proeminentes. $\mathrm{O}$ aluno A4 relaciona à educação ambiental ao ambiente escolar e o local onde estão inseridos, evidenciando uma visão ainda que superficial da participação humana no ambiente em que vive. 
É possível observar nas respostas dos alunos B1, B2 e B4, uma evidente citação das temáticas relacionadas ao lixo e poluição como objeto de estudo da Educação Ambiental. A abordagem dessas temáticas ficou estereotipada, visto que os professores optam por desenvolver atividades relacionadas ao uso adequado da água, descarte de lixo, reciclagem, restritas às datas comemorativas. Esses temas não são suficientes para cumprir o papel da Educação Ambiental crítica no currículo escolar e em todas as disciplinas com a finalidade de construir "valores sociais, conhecimentos, habilidades, atitudes e competências voltadas para a conservação do meio ambiente" (DIAS, 2004, p. 202).

Verifica-se que na maior parte das escolas públicas e privadas não existem um ensino de "Educação Ambiental que suscita uma vinculação mais estreita entre os processos educativos e a realidade, estruturando suas atividades em torno dos problemas concretos que se impõe a comunidade" (DIAS, 1991, p. 6). Esses temas possuem uma característica superficial, restrita e descontextualizada das questões socioambientais da realidade. É necessário repensar nas práticas pedagógicas que envolvem o desenvolvimento da Educação Ambiental. É na temática ambiental que a escola poderia apresentar um impacto significativo na sociedade, mediante a criação de canais de comunicação com a população que possibilitem a discussão e reflexão sobre o papel dos cidadãos quanto ao meio ambiente (VEIGA; AMORIM; BLANCO, 2005).

Zacarias (2000, p. 34) defende que

[...] a partir de um enfoque crítico, à Educação Ambiental poderá contribuir para a formação de cidadãos conscientes, aptos para se decidirem a atuar na realidade socioambiental de um modo comprometido com a vida, com o bem-estar de cada um e da sociedade local e global.

A maioria dos alunos possui uma visão de Educação Ambiental como responsável por cuidar, preservar, conscientizar, e respeitar o meio ambiente, enfatizando a questão ecológica. Não há uma relação com a desigualdade social, ao contexto social, a sustentabilidade, mas visa apenas ações humanas para reduzir os problemas ambientais.

É importante destacar, na visão de Guimarães (2007, p. 35)

Essa educação não pode e/ou não quer perceber as redes de poder que estruturam as relações de dominação presentes na sociedade atual, tanto entre pessoas (relações de gênero, de minorias étnicas e culturais), entre classes sociais, quanto na relação "norte-sul" entre as nações, assim como também entre as relações de dominação que se construíram historicamente entre sociedade e natureza. São nessas relações de poder e dominação que podemos encontrar um dos pilares da crise ambiental dos dias de hoje.

À Educação Ambiental conservadora almeja apenas mudanças culturais e de comportamento, não é uma proposta viável, pois essas não podem ser transformadas se não 
houver transformação nos sistemas econômico e político da sociedade (LAYRARGUES, 2012).

A segunda questão indagou os alunos sobre "O que significa para você o Meio Ambiente?". Esta questão teve por objetivo identificar se o aluno compreende o mundo que o rodeia para que assim visualize a sua função nesse ambiente. Selecionamos as respostas de três alunos do primeiro, segundo e terceiro ano, respectivamente, as quais estão representadas no Quadro 2.

Quadro 2 - Concepção dos alunos do Ensino Médio sobre Meio Ambiente

\begin{tabular}{|c|l|}
\hline $\begin{array}{c}\text { Identificação dos } \\
\text { alunos }\end{array}$ & \multicolumn{1}{c|}{ Respostas dos alunos } \\
\hline \multicolumn{2}{|c|}{ Concepção dos alunos do primeiro ano sobre Meio Ambiente } \\
\hline A1 & "Significa o meio em que vivemos". \\
\hline A2 & $\begin{array}{l}\text { "Meio ambiente para mim significa a natureza, florestas, rios, } \\
\text { matas". }\end{array}$ \\
\hline A3 & $\begin{array}{l}\text { "Significa o lugar onde vivemos como por exemplo as cidades, as } \\
\text { florestas". }\end{array}$ \\
\hline \multicolumn{3}{|c|}{ Concepção dos alunos do segundo ano sobre Meio Ambiente } \\
\hline B1 & "É o lar onde os animais vivem". \\
\hline B2 & "Meio ambiente é a mata, a fauna e flora". \\
\hline B3 & "Meio ambiente é o nosso planeta. É a natureza, sem poluição". \\
\hline \multicolumn{2}{|c|}{ Concepção dos alunos do terceiro ano sobre Meio Ambiente } \\
\hline C1 & "O meio ambiente é toda a natureza que nos cerca”. \\
\hline C2 & “O meio ambiente são nossas florestas, nossos rios". \\
\hline C3 & "Significa o ambiente em que vivemos. Paisagens, campos, hortas." \\
\hline
\end{tabular}

Fonte: Autoras.

Não existe, entre os especialistas, unanimidade sobre o conceito de meio ambiente. Portanto, se trata de um conceito de difícil definição, mas necessário para o desenvolvimento da Educação Ambiental.

A maioria dos alunos considera o meio ambiente como a natureza, as florestas, rios, animais, como um ambiente para apreciar, respeitar e preservar, ambientes limpos e sem poluição. Os alunos B1 e B2 apresentam a natureza como algo isolado do qual o homem não faz parte, mas apenas os outros seres vivos como participantes desse contexto. Segundo Sauvé (2005, p. 317), "é preciso reconstruir nosso sentimento de pertencer à natureza, a esse fluxo de 
vida de que participamos. Enquanto não entendermos que somos participantes do meio ambiente, não será possível modificar as ações no local em que vivemos".

A terceira questão indagou os alunos da seguinte forma: Para você o(s) professor (es) de qual(is) disciplina(s) deveria trabalhar sobre Educação Ambiental? Podemos observar no quadro 3 as disciplinas mencionadas nas respostas dos alunos do primeiro, segundo e terceiro ano, respectivamente.

\begin{tabular}{|c|c|}
\hline Disciplinas & Quantidade de respostas \\
\hline \multicolumn{2}{|c|}{ Respostas alunos do primeiro ano } \\
\hline Artes & 0 \\
\hline Biologia & 3 \\
\hline Educação Física & 0 \\
\hline Geografia & 5 \\
\hline História & 0 \\
\hline Química & 1 \\
\hline \multicolumn{2}{|c|}{ Respostas alunos do segundo ano } \\
\hline Artes & 1 \\
\hline Biologia & 6 \\
\hline Educação Física & 2 \\
\hline Geografia & 4 \\
\hline História & 1 \\
\hline Química & 0 \\
\hline \multicolumn{2}{|c|}{ Respostas alunos do terceiro ano } \\
\hline Artes & 0 \\
\hline Biologia & 6 \\
\hline Educação Física & 0 \\
\hline Geografia & 5 \\
\hline História & 3 \\
\hline Química & 0 \\
\hline
\end{tabular}

Fonte: Autoras. 
De acordo com a Lei $N^{\circ}$ 9.795, de 27 de abril de 1999, que institui a Política Nacional de Educação Ambiental, Art. $9^{\circ}$, à Educação Ambiental deve estar presente e ser desenvolvida no âmbito dos currículos das instituições de ensino público e privada. Portanto, à Educação Ambiental deve estar presente em todos os segmentos e níveis da educação formal de maneira que seja desenvolvida com uma prática educativa integrada, contínua e permanente, assim como afirma o Art. $10^{\circ}$ da mesma lei (BRASIL, 1999).

Sendo assim, à Educação Ambiental não é um "tema" restrito apenas as disciplinas que possuem na sua grade curricular conteúdos relacionados às questões ecológicas e naturalistas como os presentes nas disciplinas mais citadas pelos alunos: Biologia e Geografia, somando um total de 29 respostas. Essa soma nos faz refletir sobre o papel da escola no que diz respeito colocar em prática uma Educação Ambiental integradora, interdisciplinar e que forme alunos ativos. Deve-se superar essa visão retrocessiva relacionada à desenvolver as atividades ambientais apenas nas disciplinas mais "aptas" e capacitar professores de todas as áreas de formação acadêmica à desenvolverem em suas aulas práticas pedagógicas voltadas para discutir não apenas práticas de conscientização sobre o meio ambiente e como preservá-lo, mas também discutir às políticas públicas que interferem diretamente ou indiretamente nos problemas ambientais atuais.

De acordo com Reigota (2001, p. 25) “à Educação Ambiental, como perspectiva educativa, pode estar presente em todas as disciplinas, quando analisa temas que permitem enfocar as relações entre a humanidade e o meio natural, e as relações sociais, sem deixar de lado as suas especificidades."

Foi questionado também aos alunos "Por qual meio você se informa das questões ambientais?" Algumas alternativas foram fornecidas para a escolha dos discentes que estarão no quadro 4 seguidos das respostas dos alunos da primeira, segunda e terceira séries respectivamente.

A porcentagem dos alunos do primeiro e segundo ano são maiores na alternativa "Durante as aulas pelos professores ou em atividades desenvolvidas pela escola", ou seja, observamos aqui como é fundamental a participação da escola na formação desses alunos.

$\mathrm{Na}$ maioria das vezes é somente nesse ambiente que eles terão acesso a uma visão mais ampla e crítica sobre os temas ambientais e esse é o papel da escola levar o conhecimento, transformar as ações atitudinais e contribuir para uma sociedade com indivíduos capazes de questionar, argumentar e defender a natureza. 
Quadro 4 - Qual a forma de obter informações sobre questões ambientais, de acordo com os alunos do Ensino Médio.

\begin{tabular}{|c|c|c|c|}
\hline Opções de resposta & $\begin{array}{c}\text { Quantidade de } \\
\text { alunos do } \\
\text { primeiro ano por } \\
\text { alternativa }\end{array}$ & $\begin{array}{c}\text { Quantidade de } \\
\text { alunos do } \\
\text { segundo ano por } \\
\text { alternativa }\end{array}$ & $\begin{array}{c}\text { Quantidade de } \\
\text { alunos do } \\
\text { terceiro ano por } \\
\text { alternativa }\end{array}$ \\
\hline $\begin{array}{c}\text { Informo-me por meio de livros, } \\
\text { revistas e jornais }\end{array}$ & 1 & 1 & 3 \\
\hline $\begin{array}{c}\text { Através das mídias virtuais: } \\
\text { TV, rádio ou internet }\end{array}$ & 3 & 6 & 6 \\
\hline $\begin{array}{c}\text { Durante as aulas pelos } \\
\text { professores ou em atividades } \\
\text { desenvolvidas pela escola }\end{array}$ & 5 & 8 & 5 \\
\hline
\end{tabular}

Fonte: Autoras.

Segundo Chalita (2002, p. 34)

à educação constitui-se na mais poderosa de todas as ferramentas de intervenção no mundo para a construção de novos conceitos e consequente mudança de hábitos. É também o instrumento de construção do conhecimento e a forma com que todo o desenvolvimento intelectual conquistado é passado de uma geração a outra, permitindo, assim, a máxima comprovada de cada geração que avança um passo em relação à anterior no campo do conhecimento científico e geral.

Na visão de Guimarães (1995), o Ensino Médio, por exemplo, tem visado apenas o vestibular e se esquece da formação de cidadãos que pensem de forma crítica e que vejam o mundo e o próximo não como um adversário, mas como um cidadão.

No segundo ano a alternativa mais assinalada foi: "Através das mídias virtuais: TV, rádio ou internet." Esse é um dado preocupante, pois sabemos que muitas vezes as mídias fornecem um conhecimento superficial ou então de interesse da classe dominante podendo disseminar nos alunos uma concepção equivocada sobre as políticas públicas, preservação e manutenção do meio ambiente, formando indivíduos alienados e vulneráveis as discussões sobre os temas ambientais.

De acordo com Grossi e Santos (2007) a mídia transmite imagens ao vivo em tempo real e tem o poder de conectar-se à sociedade global e acirrar as desigualdades sociais através das diferentes formas de exclusão nos planos culturais, econômicos e sociais. Vive-se em uma sociedade midiocrática que impõe desde padrões de consumo até estéticos. A mídia tornou-se tão poderosa ao transmitir verdades hegemônicas, que muitas vezes não são questionadas, são tomadas como certezas e são incorporadas ao nosso discurso de senso comum. Segundo Nunes (2007) os meios de comunicação ocupam grande parte do tempo físico e mental dos jovens, disputando lugares na socialização. 
Por isso, a escola precisa ficar atenta e reverter esse resultado sendo ela a principal fonte de conhecimento superando a influência de senso comum transmitida pelas mídias virtuais.

A última questão buscava compreender a melhor maneira da Educação Ambiental ser ensinada pelos professores de acordo com os participantes da pesquisa. "Para você, de que maneira o professor poderia ensinar à Educação Ambiental?” Algumas alternativas foram selecionadas para as respostas. Segue no quadro 5 as respostas dos alunos do Ensino Médio.

Quadro 5 - Concepção dos alunos do Ensino Médio sobre metodologias que podem contribuir com a aprendizagem da Educação Ambiental, de acordo com os alunos pesquisados.

\begin{tabular}{|c|c|c|c|}
\hline Opções de resposta & $\begin{array}{c}\text { Quantidade } \\
\text { de alunos do } \\
\text { primeiro ano } \\
\text { por } \\
\text { alternativa }\end{array}$ & $\begin{array}{c}\text { Quantidade de } \\
\text { alunos do } \\
\text { segundo ano por } \\
\text { alternativa }\end{array}$ & $\begin{array}{c}\text { Quantidade } \\
\text { de alunos do } \\
\text { terceiro ano } \\
\text { por } \\
\text { alternativa }\end{array}$ \\
\hline $\begin{array}{c}\text { Acredito que a melhor forma de ensinar a } \\
\text { EA é através das aulas práticas e aulas de } \\
\text { campo. }\end{array}$ & 6 & 7 & 5 \\
\hline $\begin{array}{c}\text { Considero a melhor forma de se ensinar a } \\
\text { EA os debates realizados em sala e } \\
\text { palestras sobre o tema. }\end{array}$ & 3 & 5 & 6 \\
\hline $\begin{array}{c}\text { Quando durante as aulas os professores } \\
\text { relacionaram os temas estudados com } \\
\text { outras disciplinas e com meio em que vivo. }\end{array}$ & 0 & 3 & 3 \\
\hline
\end{tabular}

Fonte: Autoras.

De acordo com Araújo, Soares e Andrade (2008), as tradicionais metodologias baseadas na mera transmissão de informação, não respondem as demandas sociais do século XXI, fazendo-se necessária à busca de estratégias docentes alternativas.

Considera-se extremamente importante que o professor utilize diversas modalidades didáticas em sua prática docente, pois assim atenderá de forma mais ampla as diferenças individuais e despertará o interesse dos alunos (KRASILCHIK, 2008 apud JÚNIOR; SANTOS; JESUS, 2016). Aulas focadas apenas no método tradicional não contribuem para o desenvolvimento do pensamento crítico dos alunos.

À primeira alternativa obteve mais respostas nas três séries, isso nos mostra como há uma valorização da parte dos alunos pelas aulas práticas, por estarem em contato com o ambiente fora da sala de aula proporciona o contato com a problemática estudada, porém deve haver da parte do professor um cuidado no que cerne a esse quesito, pois as aulas práticas, as saídas a campo devem ser acompanhadas de explicação teórica e aplicação na vida dos alunos, se assim não for fica sujeita a ser mera demonstração. 
Às aulas práticas têm seu valor reconhecido. Elas estimulam a curiosidade e o interesse de alunos, permitindo que se envolvam em investigações científicas, ampliem a capacidade de resolver problemas, compreender conceitos básicos e desenvolver habilidades. Além disso, quando os alunos se deparem com resultados não previstos, desafia sua imaginação e seu raciocínio. As atividades experimentais, quando bem planejadas, são recursos importantíssimos no ensino (RONQUI; SOUZA; FREITAS, 2009).

As aulas de campo permitem a exploração de conteúdos conceituais, procedimentais e atitudinais, o que possibilitam que sejam também de grande valia em programas de Educação Ambiental (VIVEIRO; DINIZ, 2009). O contato do aluno com o objeto de estudo incentiva à preservação do ambiente, a valorização e a descoberta de fenômenos da natureza essa metodologia de ensino é uma ferramenta que deve ser explorada pelos professores.

Os debates, as palestras foram a segunda alternativa mais citada, os debates possuem a característica de confrontar os alunos, de desenvolver neles a capacidade de tomar decisões frente a situações e a se posicionaram em relação a temas de grande impacto na sociedade. Por exemplo se é proposto a dois grupos de alunos para que um seja a favor e o outro contra a construção de hidrelétricas esses alunos terão de pesquisar, argumentar, falar, criticar, debater e ao final tomar partida sobre a sua própria opinião sobre o assunto e saberá defende-la com argumentos válidos quando questionado sobre o assunto.

A palestra por sua vez tem o objetivo de levar informação de expor temáticas e a realidade muitas vezes camuflada pelas mídias e é o papel da escola levar esse conhecimento intelectual aos seus alunos desenvolvendo atividades como estas.

A alternativa menos assinalada evidencia a interdisciplinaridade e a capacidade do professor de relacionar os temas ao cotidiano do aluno. Sabe-se que é um dos princípios da Educação Ambiental aplicar um enfoque interdisciplinar, aproveitando o conteúdo específico de cada disciplina, de modo que se adquira uma perspectiva global e equilibrada (DIAS, 1991).

As práticas educativas relacionadas à questão ambiental podem assumir função transformadora, o que faz os indivíduos, depois de conscientizados, se tornarem em objetos essências para a promoção do desenvolvimento (DICKMANN; CARNEIRO, 2012).

Para que haja uma melhora no processo de ensino e aprendizagem o estudante deve ser estimulado a fundamentar seus conhecimentos já existentes, não através da substituição de suas concepções prévias pelos novos conhecimentos científicos discutidos em sala de aula, mas por meio da negociação dos novos significados e isto torna-se possível através de aulas discursivas e interativas (MORTIMER, 1996; MORTIMER; SCOTT, 2002). Ou seja, aulas que fujam do 
modelo tradicional e trabalhe à Educação Ambiental numa perspectiva interdisciplinar, crítica, social, política e transformadora.

\section{CONSIDERAÇÕEs FinAis}

Sugere-se através dos dados dessa pesquisa que os alunos possuem uma percepção conservacionista sobre o que é Educação Ambiental e Meio Ambiente e a proposta de um ensino aprendizagem crítico e emancipatório, conforme recomendação da EA critica, é limitada. Foi possível observar com preocupação, à concepção rasa e naturalista que os alunos do Ensino Médio apresentam quanto às temáticas ambientais, desligada dos contextos sociais, econômico, político e culturais nos quais se insere o ser humano. $\mathrm{O}$ desafio da escola em parceria com os professores é o de formular uma Educação Ambiental que seja crítica e transformadora. Assim à Educação Ambiental deve ser acima de tudo um ato político voltado para à transformação social. O seu enfoque deve buscar uma perspectiva holística de ação, que relaciona o homem, a natureza e o universo, tendo em conta que os recursos naturais se esgotam e que o principal responsável pela sua degradação é o homem.

\section{REFERÊNCIAS}

ARAÚJO, Maria Inês Oliveira; SOARES, Maria José Nascimento; ANDRADE, Djalma. Desafios da formação de professores para o século XXI: o que deve ser ensinado? o que é aprendido - Relatos e ensaios. São Cristóvão: Editora UFS, 2008. 177p.

BRASIL. Lei 9.795 de 27 de abril de 1999. Dispõe sobre a educação ambiental, institui a Política Nacional de Educação Ambiental e dá outras providências. Disponível em: http://www.planalto.gov.br/CCIVil_03/LEIS/L9795.htm. Acesso em: 20 ago. 2018.

CHALITA, Gabriel. Educação: a solução está no afeto. São Paulo: Gente, 2002.

DIAS, Genebaldo Freire. Os quinze anos da Educação Ambiental no Brasil: um depoimento. Em aberto, Brasília, v. 10, n. 49, p. 3-14, jan./marc., 1991. Disponível em: http://portal.inep.gov.br/documents/186968/485895/Educa\%C3\%A7\%C3\%A3o+ambiental/3 7cbac3e-3bc6-4783-bc30-017a350437b5?version=1.3 Acesso em: 05 nov. 2019.

DIAS, Genebaldo Freire. Educação Ambiental - Princípios e Práticas. 9. ed., São Paulo: Gaia, 2004.

DICKMANN, Ivo; CARNEIRO, Sônia Maria Marchiorato. Paulo Freire e Educação ambiental: contribuições a partir da obra Pedagogia da Autonomia. Revista de Educação Pública. v. 21, n. 45, p. 87-102, jan./abri. 2012. Disponível em: http://periodicoscientificos.ufmt.br/ojs/index.php/educacaopublica/article/view/334/302 Acesso em: 05 dez. 2019.

GIL, Carlos Antônio. Métodos e Técnicas de Pesquisa Social. 6. ed. São Paulo: Atlas, 2008. 
GOLDEMBERG, José. O repensar da educação no Brasil. Estudos avançados. São Paulo, v. 7, n. 18, p. 65-137, maio/ago.1993. Disponível em:

http://www.scielo.br/pdf/ea/v7n18/v7n18a04.pdf Acesso em: 03 dez. 2019.

GROSSI, Patrícia Krieger; SANTOS, Andréia Mendes dos. Infância comprada: hábitos de consumo na sociedade contemporânea. Revista Textos \& Contextos, Porto Alegre, v. 6, n. 2, p. 443-454, jul/dez, 2007. Disponível em:

http://revistaseletronicas.pucrs.br/fass/ojs/index.php/fass/article/view/2327. Acesso em: $10 \mathrm{de}$ nov. 2019.

GUIMARÃES, Mauro. A dimensão ambiental na educação. 5. ed. Campinas: Papirus,1995.

GUIMARÃES, Mauro. Educação ambiental: no consenso um embate? Campinas: Papirus, 2000 .

GUIMARÃES, Mauro. A formação de educadores ambientais. Campinas, SP: Papirus (Coleção Papirus Educação), 2007.

INEP - Instituto Nacional de Estudos e Pesquisas Educacionais Anísio Teixeira. Censo Escolar da Educação Básica 2016. Disponível em:

http://download.inep.gov.br/educacao_basica/censo_escolar/notas_estatisticas/2018/notas_est atisticas_censo_escolar_2018.pdf Acesso em: 20 nov. 2019.

JÚNIOR, Narla Mota; SANTOS, Lidiane Alves dos; JESUS, Lívia Maria Santos de.

Educação Ambiental: concepções e práticas pedagógicas de professores do ensino fundamental da rede pública e privada em Itabaiana, Sergipe. REMEA - Revista Eletrônica Mestrado em Educação Ambiental, volume especial, p. 2013-236, 2016. Disponível em: https://periodicos.furg.br/remea/article/view/5384/4353 Acesso em: 06 nov. 2019.

LAYRARGUES, Philippe Pomier. Para onde vai a Educação Ambiental? O cenário políticoideológico da Educação Ambiental brasileira e os desafios de uma agenda política crítica contra hegemônica. Revista Contemporânea de Educação, Rio de Janeiro, v. 7, n. 14, p. 388- 411, 2012. Disponível em: https://revistas.ufrj.br/index.php/rce/article/view/1677/1526. Acessado em: 03 dez. 2019.

MORTIMER, Eduardo Fleury. Construtivismo, mudança conceitual e ensino de ciências: para onde vamos? Investigações em Ensino de Ciências, Porto Alegre, v. 1, n. 1, p. 20-39, 1996. Disponível em: https://www.if.ufrgs.br/cref/ojs/index.php/ienci/article/view/645 Acesso em: 06 dez. 2019.

MORTIMER, Eduardo Fleury; SCOTT, Phil. Atividade discursiva nas salas de aula de ciências: uma ferramenta sociocultural para analisar e planejar o ensino. Investigações em Ensino de Ciências, Porto Alegre, v. 7, n. 3, p. 283-306, 2002. Disponível em: https://www.if.ufrgs.br/cref/ojs/index.php/ienci/article/view/562/355 Acesso em: 01 nov. 2019.

NUNES, Brasilmar Ferreira. Consumo e identidade no meio juvenil: considerações a partir de uma área popular do Distrito Federal. Sociedade e Estado, Brasília, v. 22, n. 3, p. 647-678, 2007. Disponível em: http://www.scielo.br/pdf/se/v22n3/07.pdf Acesso em: 02 dez. 2019. 
PÉREZ GÓMEZ, Ángel Ignacio. As funções sociais da escola: da reprodução à reconstrução crítica do conhecimento e da experiência. In: GIMENO SACRISTÁN, José.; PÉREZ GÓMEZ, Ángel Ignacio. (Orgs.). Compreender e transformar o ensino. 4. ed. Porto Alegre: Artes Médicas, 1998.

REIGOTA, Marcos. Desafios à educação ambiental escolar. In: JACOBI, Pedro. Educação, meio ambiente e cidadania: reflexões e experiências. São Paulo: SMA, 1998. p. 43-50.

REIGOTA, Marcos. O que é educação ambiental. 1. ed. São Paulo: Brasiliense, 2001.

RONQUI, Ludimilla; SOUZA, Marco Rodrigo de; FREITAS, Fernando Jorge Coreia de. A importância das atividades práticas na área de biologia. Revista científica da Faculdade de Ciências Biomédicas de Cacoal - FACIMED. Cacoal - RO, v. 1, p. 1-9, 2009. Disponível em: http://www.facimed.edu.br/site/revista/pdfs/8ffe7dd07b3dd05b4628519d0e554f12.pdf Acesso em: 03dez. 2018.

SAUVÉ. Lucie. Educação Ambiental: possibilidades e limitações. Educação e Pesquisa, v. 31, n. 2, p. 317-322, maio/ago. 2005. Disponível em:

http://www.revistas.usp.br/ep/article/view/27979 Acesso em: 20 jun. 2018.

TOZONI-REIS, Marília Freitas de Campos. Educação Ambiental referências teóricas no ensino superior. Interface, Botucatu, v. 5, n. 6, p. 33-50 2001. Disponível em:

http://www.scielo.br/pdf/icse/v5n9/03.pdf Acesso em: 20 dez. 2018.

TOZONI-REIS, Marília Freitas de Campos. Educação Ambiental, natureza, razão e história. Campinas: Autores Associados, 2004.

VEIGA, Alinne; AMORIM, Érica; BLANCO, Mauricio. Um retrato da Presença da Educação Ambiental no Ensino Fundamental Brasileiro: o percurso de um processo de expansão acelerado. Ministério da Educação-MEC, INEP. Brasília-DF, 2005.

VIVEIRO, Alessandra Aparecida; DINIZ, Renato Eugênio da Silva. Atividades de campo no ensino das ciências e na educação ambiental: refletindo sobre as potencialidades desta estratégia na prática escolar. Ciência em Tela. v. 2, n. 1, p. 1-12, 2009. Disponível em: http://www.cienciaemtela.nutes.ufrj.br/artigos/0109viveiro.pdf Acesso em: 20 jul. 2018.

ZACARIAS, Rachel. Consumo, lixo e educação ambiental: uma abordagem crítica. Juiz de Fora: FEME, 2000.

Recebido em: 09 de dezembro de 2019.

Aprovado em: 15 de abril de 2020. 